\title{
Organização do trabalho e processo decisório em cooperativas populares e tradicionais: estudo de casos em duas cooperativas paranaenses
}

Farid Eid $^{1}$

Caio Luis Chiariello²

Resumo: O artigo analisa a dinâmica da democracia interna e da organização do trabalho em cooperativas tradicionais e populares, como parte integrante do debate teórico acerca da gestão de cooperativas que ocorre a partir da década de 1990. Com base no referencial sobre as duas modalidades de cooperativas e na investigação empírica junto a uma cooperativa tradicional - COCAMAR - e a uma cooperativa popular - COPAVI, buscou-se identificar, nos dois casos, a orientação desses empreendimentos para heterogestão ou autogestão.

Palavras-chave: organização do trabalho; democracia interna; cooperativas tradicionais; cooperativas populares.

\section{Work organization and decision process in popular and traditional cooperatives: case study in two cooperative firms in Parana State}

\begin{abstract}
This article analyzes the dynamics of democracy and work organization in traditional and popular cooperatives, as part of the debate about the management of cooperatives taking place since the 199os. Based on the theoretical referential about both modalities of cooperatives and on the empirical inquiry on a traditional cooperative - COCAMAR - and on a popular cooperative - COPAVI, we have tried to identify the orientation of these enterprises as for the heteromanagement or self-management alternatives.
\end{abstract}

Keywords: work organization; internal democracy; traditional cooperatives; popular cooperatives.

JEL: P130

1 Professor do Departamento de Engenharia de Produção da Universidade Federal de São Carlos - UFSCAR. E-mail: farid@ufscar.br.

2 Doutorando em Engenharia de Produção pela Universidade Federal de São Carlos - UFSCAR. E-mail: mudomundo@hotmail.com 


\section{Introdução}

Inspiradas nos movimentos cooperativistas europeus, as primeiras experiências do cooperativismo brasileiro datam do final do século XIX, e caminharam muito lentamente até a crise da década de 1930. As experiências principalmente na região sul do país, despertaram o interesse do governo do Estado Novo pelo cooperativismo. O cooperativismo entra na pauta da política agrícola nacional, como forma de defender a produção em pequena propriedade, estimulando a policultura e o desenvolvimento do mercado interno, sem, no entanto, cogitar o desmonte da estrutura latifundiária de produção ou dissolução da grande propriedade rural. (Benetti 1985).

Durante décadas, o Estado fomentou a formação de cooperativas, exercendo, paralelamente, intenso controle sobre suas atividades. Na percepção de alguns autores (Fleury 1980; Duarte 1986), durante o período que vai de 1930 até a promulgação da Constituição de 1988, as cooperativas foram utilizadas como instrumento para a imposição das determinações do Estado no setor agrícola e, principalmente, para acumulação privada de capital. A partir de 1988, com menor intervenção do Estado, o movimento cooperativista brasileiro vem se apresentando gradualmente sob duas vertentes distintas: uma, diz respeito ao cooperativismo tradicional, empenhado em apresentar eficiência econômica e financeira em detrimento da eficiência social, enquanto a outra, ligada aos movimentos sociais, procura revitalizar valores e princípios advindos do socialismo utópico e hoje vinculados a Sócio-Economia Popular e Solidária.

A partir da década de 1990, a vertente do cooperativismo ligada à Economia Solidária tem se preocupado em contribuir para a renovação e atualização histórica das concepções da Economia Social, atuando junto aos hiatos deixados pela insuficiência do mercado e negligência do Estado com relação às demandas por trabalho, renda e existência digna de muitos trabalhadores (França Filho 2002). Tais ideias se confrontam com a visão liberal, que entende a Economia Solidária enquanto uma forma alternativa de participação na economia capitalista, corrigindo distúrbios sazonais do mercado de trabalho com ações coletivas capitaneadas pela sociedade civil para manutenção dos postos de trabalho. Segundo a tese liberal, empreendimentos de Economia Solidária apenas preenchem as lacunas deixadas pelas imperfeições do mercado, inscrito no modo de produção capitalista, e se consolidam precariamente, dado que os trabalhadores optam por se associarem às cooperativas em razão da falta de acesso ao emprego formal. Em momentos pós-crise, e de relativo aumento da atividade econômica, as possibilidades de retorno ao emprego assalariado atrairia a gama de trabalhadores cooperados, esvaziando os empreendimentos coletivos.

Porém, a partir da década de 1980, observa-se um descolamento crescente no pressuposto de que um aumento de produção acarretaria proporcionalmente um aumento do emprego, contrariando a proposição liberal de equilíbrio 
pelas livres forças de mercado. Vislumbramos o fenômeno do crescimento com desemprego (Lisboa 2005). Diante desse novo quadro, vem a tona o debate teórico entre percepções distintas acerca da orientação da gestão nas cooperativas. Se por um lado a vertente teórica defensora do cooperativismo empresarial atesta que o empreendimento cooperativo, ao se desenvolver, deve ajustar-se à mesma lógica da empresa capitalista, a vertente teórica ligada às cooperativas oriundas de movimentos sociais defende que estas se desenvolvam economicamente, mas aprofundando a construção da autogestão em seu interior.

\section{Processo decisório e organização do trabalho em cooperativas tradicionais}

Em se tratando de democracia interna nas cooperativas, a Assembleia Geral é a instância última de deliberação sobre todas as ações vitais da cooperativa. As decisões respeitam uma determinação pela base, e ao coletivo do empreendimento cabe aprovar ou vetar as propostas oriundas dos órgãos de administração ou conselhos. Estes órgãos são responsáveis pela gestão propriamente dita da cooperativa, sendo compostos por membros escolhidos por seus diversos setores, imbuídos de competência para elaborar propostas de gestão, submetê-las à assembleia e executá-las em caso de aprovação. Ocorre que, para alguns autores, tal modelo de organização administrativa na cooperativa acaba por confundir as esferas de propriedade e de controle, gerando impasses em sua gestão. Zilberstajn (2005:60) argumenta que, com o aumento da complexidade nas atividades da cooperativa, haveria ganho com a separação entre propriedade e controle da empresa. Segundo o autor, se a expansão é o objetivo principal das cooperativas, suas atividades mais complexas devem ser gerenciadas por profissionais contratados.

A profissionalização do gerenciamento das cooperativas pode levar às seguintes situações de melhoria de seu desempenho: a) agilidade na tomada de decisões pontuais para a administração das atividades (produção, finanças, comercialização), reduzindo custos de transação (Bialoskorsky Neto 1998); b) maior simetria das informações entre associado e cooperativa, agente e principal (Costa 2005); c) maior sintonia entre produção e sinalização dos mercados (Bialoskorsky Neto 2002); d) maior propensão à centralização e/ ou fusão com outras cooperativas (Panzutti 1996); e) redução de possíveis favorecimentos a grupos de cooperados ligados a membros dos conselhos (Menegario 2000).

Nesse sentido, a organização do trabalho nos empreendimentos cooperativos remete a uma questão crucial: o entendimento das cooperativas enquanto empresas de trabalho que não visam lucro poderia estar determinando o ponto ótimo de eficiência de operações na maximização de serviços e não de ganhos (Bialoskorsky Neto 1998). O aspecto coletivo da cooperativa levaria 
à deformação do conceito de eficiência econômica da empresa. As cooperativas, quando visam a simples subsistência de seus cooperados em pequenos empreendimentos, negligenciam o componente competitivo e se abstêm de galgar um posicionamento agressivo diante do mercado (Bialoskorsky Neto 2001). Assim, o trabalhador cooperado, assumindo a função de gestor/empresário, se vê diante de um dilema: se resignar com sua condição de provedor da subsistência ou assumir a missão de fazer o empreendimento crescer, lançando mão de elementos da administração científica e suas ferramentas gerenciais.

Levy (2001: 108) alerta para o fato de que, no contexto da globalização, a economia agrícola demanda a utilização de ferramentas de gestão que privilegiem a eficiência ao mutualismo. Para o autor, os antigos princípios da cooperação parecem não ser mais suficientes para a permanência da cooperativa em um cenário global sob o paradigma neoliberal. Logo, para os cooperados, seria melhor optar por gerir a cooperativa utilizando-se da divisão do trabalho em atividades internas de produção, enquanto a gestão das cooperativas se daria em conformidade com os postulados tayloristas. A esfera de planejamento e o núcleo das decisões estratégicas se concentrariam na cooperativa, ao passo que nas atividades produtivas seria utilizado o trabalho assalariado, com trabalhadores não associados à cooperativa, mas sim prestadores de serviços aos proprietários/produtores, estes sim cooperados.

A cooperativa passaria a ser gerida pelos proprietários dos meios de produção, mas as relações internas de trabalho nas propriedades não diriam respeito à cooperativa, sendo orientadas segundo a lógica capitalista. Para Panzutti (1996:70), isso ocorre devido à existência de dois ambientes distintos de atuação da cooperativa: o ambiente dos associados e o ambiente de mercado. Em estudo realizado junto a cooperativas nos E.U.A e Canadá - denominadas Nova Geração de Cooperativas - Bialoskorsky Neto (2002: 12) constatou que, já no início das atividades da cooperativa,

agricultores são selecionados com o objetivo claro de estabelecer uma planta de
processamento para agregação de valor às commodities agropecuárias. A visão e
o objetivo final são do mercado e não do produtor, desse modo, essa organização
é ‘market oriented', e não apenas 'producer oriented', como é comum no processo
de formação de cooperativas.

O tipo de estratégia adotada por estes empreendimentos para formulação do seu quadro societário flui no sentido de fortalecer a empresa com associados que disponham de estrutura produtiva adequada para o desafio competitivo do agronegócio. Pequenos produtores que buscam na cooperativa um dispositivo de amenizar suas deficiências econômicas, extraindo da empresa o máximo de serviços possíveis, não acrescentariam muito para a maximização da eficiência, sendo sua presença nas cooperativas competitivas não mais desejada. Ainda segundo o autor, os empreendimentos cooperativos, para se equipararem às 
empresas concorrentes, precisam incrementar a eficiência em suas atividades, terceirizando serviços e contratando profissionais polivalentes para a administração e o gerenciamento. A profissionalização dos trabalhadores passa a determinar as relações de trabalho dentro das propriedades dos cooperados em conformidade com o padrão das empresas de capital participantes do agribusinees, suas concorrentes diretas.

Para analisar a dinâmica da democracia interna e da organização do trabalho em uma cooperativa tradicional, foi realizado o estudo de caso na COCAMAR.

\subsection{Democracia interna e organização do trabalho na Co- operativa dos Cafeicultores e Agropecuaristas de Maringá - COCAMAR}

A organização interna da COCAMAR contempla seus aspectos político e produtivo. $\mathrm{O}$ aspecto político diz respeito às questões de interesse direto dos sócios, através das instâncias responsáveis pela direção da cooperativa, que representam os cooperados e são por eles instituídas. Já o aspecto produtivo remete ao núcleo técnico da cooperativa, responsável pelas atividades produtivas, comerciais e que prestam assistência técnica, além da gestão dos negócios da COCAMAR.

Ao longo da década de 1990, a cooperativa implementou uma reestruturação na sua organização interna, visando profissionalizar suas atividades e alcançar maior eficiência em seu processo decisório. A direção executiva da cooperativa passou de sete para três componentes e vários departamentos foram agrupados ou extintos, em razão da política de terceirização implantada para reduzir sua estrutura, considerada excessivamente onerosa e ineficaz. A estrutura organizacional da COCAMAR, em 2007, pode ser visualizada na Figura 1, que é explicada na sequência. 
FIGURA 1- ESTRUTURA ORGANIZACIONAL DA COCAMAR

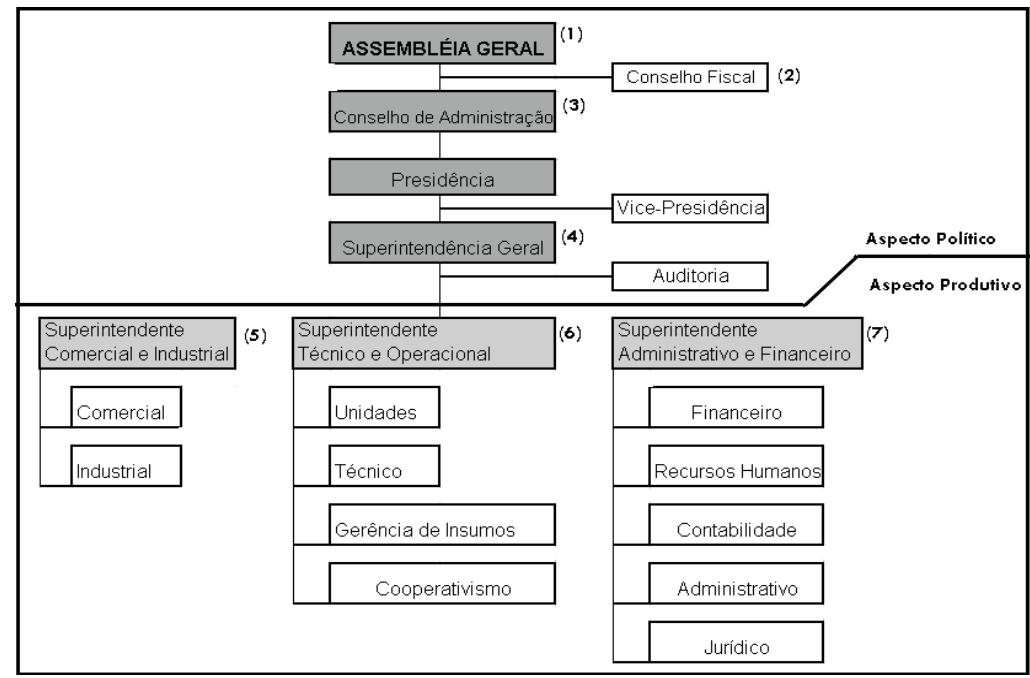

Fonte: dados fornecidos pela COCAMAR. Elaborado com dados da pesquisa de campo realizada em novembro de 2007.

(1) Assembleia Geral: instância máxima de deliberação dentro da cooperativa. È formada por todos os cooperados - cada um com direito a um voto - e realizada pelo menos duas vezes ao ano. A cooperativa realiza, em todas as suas unidades, pré-assembleias, geralmente um mês antes da realização da Assembleia Geral. Ocorre que, pelas dificuldades dos pequenos produtores em se deslocarem para participar das reuniões em Maringá, o quorum das assembleias é composto principalmente pelos grandes produtores, que fazem valer seus interesses nas deliberações.

(2) Conselho Fiscal: é o órgão responsável pela fiscalização do conselho administrativo, superintendências e setores, bem como pela preservação do patrimônio dos sócios. O conselho é composto por seis membros para um ano de gestão, atuando de forma independente de outros órgãos, pois se remete diretamente à assembleia.

(3) Conselho de administração: composto por doze representantes eleitos a cada quatro anos, sendo que três deles integram a diretoria executiva. $\mathrm{O}$ órgão é responsável pela gestão da COCAMAR, respondendo pelos resultados econômicos e pela execução das deliberações da Assembleia Geral. Mesmo tendo por princípio a alternância e representatividade nos cargos de direção, parte dos membros se mantém por mais de dez anos no conselho, havendo apenas certo rodízio nos cargo da diretoria executiva, o que demonstra rigidez no núcleo responsável pela direção da cooperativa. 
(4) Superintendências: todas possuem um superintendente geral e respondem pelas atividades produtivas, comerciais, administrativas e financeiras e de assistência técnica aos cooperados. Contemplam o aspecto produtivo da cooperativa e são compostas por funcionários contratados.

(4.1) Superintendência comercial e industrial: é responsável pela produção e comercialização da cooperativa, subdividida nos setores Industrial e Comercial.

(4.2) Superintendência técnica e operacional: fornece suporte técnico para as atividades produtivas da COCAMAR, com os seguintes setores: Unidades, Técnico, Gerência de insumos e Cooperativismo.

(4.3) Superintendência administrativa e financeira: responde pelas atividades administrativas da COCAMAR e é formada pelos setores Financeiro, Recursos humanos, Contabilidade, Administrativo e Jurídico.

Os setores responsáveis pelo aspecto produtivo da cooperativa, a partir das superintendências, são caracterizados pelo alto grau de profissionalização e independência de seus procedimentos em relação ao corpo de cooperados. No interior da cooperativa, as decisões referentes à produção, comercialização e assistência aos cooperados, são tomadas em consonância com a racionalidade econômica.

Nesse sentido, a organização do trabalho na COCAMAR se orienta pela prática da heterogestão. Tanto a Assembleia Geral quanto o conselho de administração são formados exclusivamente por sócios cooperados, mas, a partir dos núcleos responsáveis pela execução das atividades programáticas, ou seja, as superintendências, todas as demais instâncias são constituídas por profissionais contratados. Esses profissionais passam a ser empregados da cooperativa, estabelecendo com esta uma relação de trabalho assalariado e, portanto, alheios ao processo decisório.

O quadro de funcionários da COCAMAR, em 2006, era de 2220 trabalhadores. A cooperativa contava, no mesmo ano, com 6631 sócios. A evolução do número de cooperados e funcionários da cooperativa pode ser visualizada na Tabela 1. 
EID, F. \& CHIARIELLO, C. Organização do trabalho e processo decisório em cooperativas...

TABELA 1- COOPERADOS E FUNCIONÁRIOS DA COCAMAR (1994-2005)

\begin{tabular}{ccc}
\hline Ano & Cooperados & Funcionários \\
\hline 1994 & 7879 & 2880 \\
1995 & 6598 & 2470 \\
1996 & 6119 & 2400 \\
1997 & 5771 & 2062 \\
1998 & 5544 & 1800 \\
1999 & 5446 & 2400 \\
2000 & 4078 & 2530 \\
2001 & 5460 & 2600 \\
2002 & 5500 & 2700 \\
2003 & 5485 & 2580 \\
2004 & 6083 & 2620 \\
2005 & 6280 & 2410 \\
2006 & 6631 & 2220
\end{tabular}

Fonte: dados fornecidos pela COCAMAR. Elaborado com dados da pesquisa de campo realizada em novembro de 2007.

A organização do trabalho nas propriedades dos cooperados se dá por assalariamento, principalmente na produção da commodity soja, mas também ocorre utilização de mão de obra familiar nas pequenas propriedades ligadas à produção de café. A COCAMAR contribui para a execução do trabalho nas propriedades dos sócios através da assessoria técnica prestada diretamente na produção. A cooperativa não interfere na relação entre os cooperados e seus empregados, mas participa de projetos para melhoria das condições de trabalho, como o projeto Sucojusto, que contempla os trabalhadores rurais do setor cítrico na região de Paranavaí-PR (COCAMAR 2006).

No que tange à relação da cooperativa com seu sócio, a COCAMAR realiza, desde a década de 1990, um planejamento de médio prazo para adequação do quadro social. Santos (2001: 152) relata que, em 1990, a cooperativa deu início a uma política de reclassificação de seus sócios, em função do montante transacionado com a cooperativa. Os que mais movimentavam foram classificados como atuantes, os que tinham movimentação média foram classificados como integrados e os sócios com pouca movimentação foram classificados na rubrica de potenciais. Como pode ser observado na Tabela 2, no período de novembro de 1990 a setembro de 1992, os sócios classificados como potenciais, se eram $61 \%$ do total de cooperados no início do período, no final não sobraria um sequer, o que se pode supor migração parcial para sócios atuantes, já que estes apresentam crescimento considerável. De toda forma, ocorre uma forte redução no número de sócios. 
TABELA 2- EVOLUÇÃO DA CLASSIFICAÇÃO DE SÓCIOS NA COCAMAR

\begin{tabular}{lcccccc}
\hline Categoria & Nov/90 & \% & Nov/91 & $\%$ & Set/92 & $\%$ \\
Atuante & 1.159 & 7,1 & 1.409 & 10,0 & 3.873 & 38,80 \\
Integrado & 5.191 & 31,9 & 6.366 & 46,0 & 6.099 & 61,20 \\
Potencial & 9.926 & 61,0 & 6.082 & 44,0 & - & - \\
TOTAL & 16.276 & 100,0 & 13.857 & 100,0 & 9.972 & 100,0 \\
\hline
\end{tabular}

Fonte: Santos (2001).

De novembro de 1989 a setembro de 1992, o quadro de sócios da COCAMAR decresceu de 19.809 para 9.972 cooperados. Houve 3.145 demissões voluntárias, exclusão de 7.654 sócios e admissão de 1.020 cooperados (Santos 2001). No mesmo período, foram demitidos cerca de 400 funcionários e suspensos alguns benefícios, como seguros e cestas básicas, além de um corte de $20 \%$ sobre os maiores salários, o que acarretou em uma economia de $\mathrm{R} \$ 700$ mil mensais.

Essa reformulação foi tida pela cooperativa como imprescindível para imprimir uma gestão empresarial dos negócios, com o quadro de cooperados formados por produtores eficientes, dispostos a transacionar intensamente com a cooperativa, repelindo os que visavam apenas tirar proveito de sua condição de cooperado. A renovação do corpo de associados foi acompanhada por outras iniciativas: seleção mais criteriosa de novos sócios; monitoramento das atividades dos cooperados; elaboração de um cadastro informativo sobre as condições produtivas e a movimentação de cada associado com a cooperativa.

Ainda segundo a COCAMAR, são as transações com a cooperativa que garantem a continuidade das atividades do produtor, pois há pontualidade no repasse de insumos e no pagamento pela entrega da produção, ou seja, é o relacionamento econômico com a cooperativa que garante, para a maioria dos sócios, grande parte de seus rendimentos. O que a cooperativa exige do seu cooperado é sua fidelidade e aplicação na eficácia da produção, de forma a permitir ganhos de escala e o crescimento do empreendimento cooperativo, que, em 2007, apresentou um faturamento de R \$ 1,1 bilhão. 
EID, F. \& CHIARIELLO, C. Organização do trabalho e processo decisório em cooperativas...

\section{Processo decisório e organização do trabalho em cooperativas populares}

As cooperativas populares buscam exercer a gestão de suas atividades sob os princípios da autogestão, em que o planejamento e a execução das atividades se dão coletivamente de forma transparente, com rotatividade de dirigentes e tomada de decisões em conjunto pelos quadros técnicos (Cruz 2006). Espera-se que, em cooperativas populares, haja o esforço para o exercício da autogestão, de forma a distingui-la da gestão da empresa capitalista, uma vez que esta

aplica a heterogestão, ou seja, a administração hierárquica, formada por níveis sucessivos de autoridade, entre os quais as informações e consultas fluem de baixo para cima e as ordens e instruções de cima para baixo. Os trabalhadores do nível mais baixo sabem muito pouco além do necessário para que cumpram suas tarefas, que tendem a ser repetitivas e rotineiras. (Singer 2002: 16).

Em oposição ao distanciamento entre os núcleos deliberativo e executor que se manifesta na empresa heterogerida, nas cooperativas populares

estabelecem-se hierarquias de coordenadores, encarregados ou gestores, cujo funcionamento é o oposto do de seus congêneres capitalistas. As ordens e instruções devem fluir de baixo para cima e as demandas e informações de cima para baixo. Os níveis mais altos, na autogestão, são delegados pelos mais baixos e responsáveis perante os mesmos. (Singer 2002: 18).

Em tese, a autogestão inverte as relações de mando percebidas nas empresas capitalistas: nestas, um corpo de proprietários/gerentes realiza o planejamento das atividades e determina a divisão do trabalho, as metas a serem atingidas e as penalidades a serem impostas. Já na autogestão, pretende-se que todas as decisões que contemplem o planejamento das atividades, as finanças, a execução do trabalho e a busca por resultados, sejam submetidas ao coletivo. A participação efetiva dos associados se dá via Assembleia Geral, fazendo com que o poder de mando real emane das decisões dos próprios trabalhadores que devem ter seu estrito cumprimento pelos níveis administrativos, também compostos por sócios.

As cooperativas populares, no exercício da autogestão, buscam garantir o exercício da democracia sem negligenciar a eficácia das resoluções coletivas, mediante discernimento sobre as decisões a serem tomadas e seu grau de importância. Se os detalhes de cada atividade do empreendimento tiverem de ser levados à apreciação coletiva via assembleia, as atividades se inviabilizam. Outro aspecto fundamental para o êxito da autogestão é a disposição dos associados em tomarem para si as funções de trabalhador e de administrador. Essa dupla função leva o cooperado a estender seu interesse por todas as atividades 
da cooperativa e não somente para o setor em que atua. A tarefa de ser um trabalhador e ao mesmo tempo gestor do negócio representa um desafio, pois os trabalhadores geralmente estão capacitados para produzir, mas não para gerir uma empresa. Tal desafio demanda uma transformação cultural, com a emergência de novos modelos de conduta (Tauile 2006; Gaiger 2006).

Entendidos como associações igualitárias em relação à propriedade dos meios de produção, as cooperativas populares transportam a coletivização da propriedade para as questões relativas à administração e à produção material. Essa democratização do poder deliberativo permeia a estrutura produtiva e a organização do trabalho, afrouxando as hierarquias e o ordenamento 'de cima para baixo', como verificado nos postulados da administração científica. Nesse ponto, a postura dos empreendimentos solidários deve reforçar o conceito de politecnia em detrimento da polivalência. A politecnia se baseia no rearranjo dos saberes sobre o trabalho, possibilitando a universalização dos conhecimentos gerais, sem limitá-los a uma única atividade, profissão, ou classe social, sendo os trabalhadores dotados do conhecimento indissolúvel acerca dos aspectos manual e intelectual do trabalho. Para Saviani (1987: 15):

A separação dessas funções é um processo formal, abstrato, em que os elementos dominantemente intelectuais se sistematizam como tarefas de um determinado grupo da sociedade. ... a união entre trabalho intelectual e trabalho manual só poderá se realizar sobre a base da superação da apropriação privada dos meios de produção, colocando todo o processo produtivo a serviço da coletividade, no conjunto da sociedade.

Assim, a aplicação da autogestão sugere que, pela coletivização dos meios de produção, o conhecimento relativo tanto ao planejamento quanto à execução das atividades seja de domínio de todo o corpo de trabalhadores politécnicos, combinando múltiplas técnicas, que tenham sua utilização definida por eles próprios, de maneira a reafirmar sua autodeterminação.

Segundo Christoffoli (1998:64), nas cooperativas de produção agropecuária (CPAs), do MST, todo associado está vinculado a um setor de trabalho, que executa o planejamento das tarefas, com coordenadores setoriais a distribuírem funções previamente acordadas. As decisões referentes ao planejamento são coletivas e a divisão técnica do trabalho é aplicada no rodízio das tarefas e na alternância nos postos de coordenação dos setores, das comissões e conselhos dentro do empreendimento, possibilitando o aprimoramento dos trabalhadores nas aptidões técnico-produtivas e técnico-administrativas.

Outra questão fundamental, que emerge ao se tratar da organização do trabalho cooperado, diz respeito ao controle e mensuração do tempo trabalhado pelos cooperados nos coletivos, para efeito da distribuição das sobras como forma de remuneração do trabalho. Essa questão muitas vezes se apresenta como um dos maiores problemas das cooperativas de produção. Nas CPAs, 
estão presentes quatro modalidades de controle e medição do trabalho para fins da remuneração dos trabalhadores: a) distribuição igualitária per capita; b) controle por dias trabalhados; c) controle por horas trabalhadas; d) controle das horas somado à produtividade do trabalho (Concrab 1996). O sistema de controle do trabalho e distribuição das sobras é um tema delicado, que demanda uma profunda reflexão a este respeito. Christoffoli (1998: 72) defende a aplicação de metas de produtividade para definição da distribuição das sobras. No entanto, o próprio MST alerta para a possibilidade de sectarismo no interior da cooperativa: com a sobrevalorização de setores ligados à produção de gêneros de alto valor agregado, setores que não representam resultados econômicos expressivos seriam negligenciados (Concrab 2006).

Para Tauile (2006: 6) é importante que, no interior do empreendimento, a configuração da organização do trabalho leve o trabalhador a se sentir efetivamente um integrante do coletivo, estabelecendo-se relações de igualdade. Pretende-se que as cooperativas populares aprimorem a formação de trabalhadores-gestores, politécnicos, suplantando o trabalho assalariado e a divisão típica entre as esferas de propriedade (remuneração do capital), decisão (melhor remunerada) e execução (baixa remuneração). Para melhor compreendermos os desdobramentos da gestão de uma cooperativa popular, será apresentado, a seguir, o estudo de caso da COPAVI.

\subsection{Democracia interna e organização do trabalho na Co- operativa de Produção Agropecuária Vitória - COPAVI}

A questão da democracia interna, na COPAVI, é compreendida pelos cooperados como um processo dinâmico e em construção, ou seja, um aprendizado contínuo. O quadro social da COPAVI, em 2007, era formado por 43 sócios cooperados; 86 moradores na agrovila (entre cooperados e familiares não cooperados); o6 cooperados liberados para realização de curso superior em convênio com o M.S.T. e 02 cooperados liberados para atuar junto aos quadros do MST.

A entrada de um novo sócio na cooperativa se faz mediante as seguintes exigências: a) idade acima de 18 anos; b) subscrição da quota-parte (nunca superior a 01 salário mínimo vigente); c) aceitação por parte da Assembleia Geral, sendo que a aceitação de um novo sócio, por parte dos cooperados, leva em consideração requisitos não apenas econômicos. O ingresso de um novo sócio na COPAVI ainda é precedido por estágio probatório na cooperativa, quando são observadas a disposição para o trabalho e a contribuição para o coletivo, através de um bom relacionamento com os demais cooperados. Já o desligamento de um sócio está condicionado a critérios técnicos e sociais.

A organização interna da cooperativa contempla ao mesmo tempo o aspecto político e o produtivo. $\mathrm{O}$ primeiro remete à organização entre os sócios, 
enquanto o segundo contempla a execução das decisões tomadas no âmbito político.

A estrutura organizacional da COPAVI, no ano de 2007, pode ser visualizada na Figura 2 e é explicada em seguida.

FIGURA 2- ESTRUTURA ORGANIZACIONAL DA COPAVI EM 2007

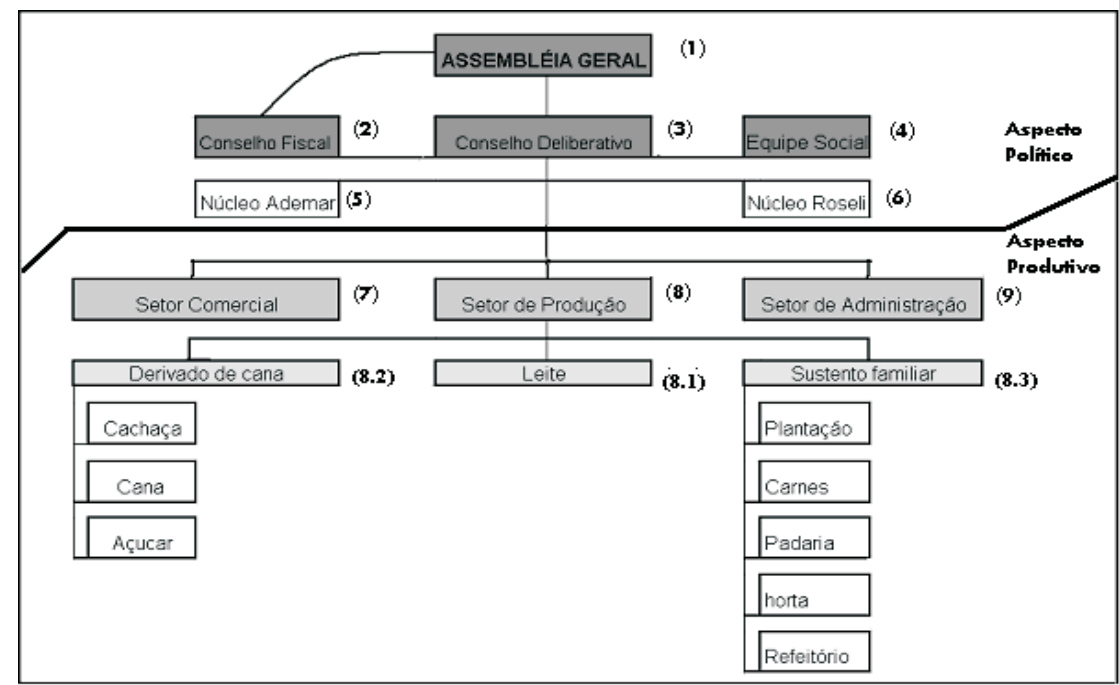

Fonte: dados fornecidos pela COPAVI. Elaborado com dados da pesquisa de campo realizada em novembro de 2007.

(1) Assembleia Geral dos sócios: realizada mensalmente, é a instância máxima de deliberação na cooperativa, com cada sócio tendo direito a um voto. Representa a confluência dos aspectos político e produtivo, sendo a presença de todos os sócios obrigatória.

(2) Conselho fiscal: órgão independente do conselho deliberativo e que tem por atribuições resguardar o patrimônio da cooperativa, conferir as horas trabalhadas pelos cooperados e fiscalizar as atividades dos setores. É composto por três sócios.

(3) Conselho deliberativo: forma a direção legal da cooperativa e é composto pelo presidente, secretário-geral, tesoureiro e por todos os coordenadores dos setores. O conselho deliberativo é eleito para um mandato de três anos. Ao conselho deliberativo compete representar externamente a cooperativa em questões políticas, econômicas e jurídicas.

(4) Equipe Social: responsável por debater assuntos ligados ao relacionamento entre os cooperados, promover a coalizão em torno de objetivos comuns e equacionar problemas mais sérios de relacionamento, quando já discutidos nos núcleos das famílias. 
EID, F. \& CHIARIELLO, C. Organização do trabalho e processo decisório em cooperativas...

(5) e (6) Núcleos das famílias (núcleo Ademar e núcleo Roseli): são o suporte social da COPAVI. Aglutinam as demandas pessoais dos sócios, além de auxiliar na conciliação de interesses conflitantes entre cooperados.

(7) Setor comercial: responsável pela comercialização dos produtos da cooperativa nas cidades próximas (vendas 'de porta em porta'), nas lojas de produtos de reforma agrária e no atacado, sendo o elo de ligação da COPAVI com os clientes externos.

(8) Setor de produção: responde por toda a atividade produtiva da COPAVI, na produção de gêneros tanto para o autoconsumo quanto para a comercialização. O setor de produção subdivide-se em outros três subsetores: (8.1) Leite: com uma produção de aproximadamente 600 litros/dia, corresponde à cadeia produtiva interna do leite; (8.2) Derivado de cana: é o subsetor que proporciona maior renda monetária para a COPAVI e é composto pelos seguintes segmentos: cachaça, cana-de-açúcar e açúcar mascavo; (8.3) Sustento familiar: responsável por prover os cooperados de gêneros alimentícios para seu sustento. O subsetor possui os seguintes segmentos: plantação e horta; carnes; padaria e refeitório.

(9) Setor de administração: responde pela organização contábil na administração da cooperativa e de suas atividades. Mantêm um escritório instalado na cooperativa.

Em todos os subsetores há um trabalhador responsável pelas atividades e que se remete ao coordenador do setor. Todos os setores e também os núcleos de famílias são representados por coordenadores, que compõem a comissão de coordenadores da cooperativa. A comissão tem por função promover discussões a respeito do andamento das atividades dos setores e buscar, conjuntamente, a melhora no desempenho global.

Um ponto relevante, em se tratando de democracia interna na COPAVI, é o fato de os sócios alocados em setores ligados à administração e conselhos integrarem os demais setores como trabalhadores na produção. Pode ocorrer situações em que um membro da direção seja subordinado ao coordenador de um setor de produção, por sua vez subordinado à direção administrativa. Isso proporcionaria uma inversão de mando que pode ser positiva, pois a hierarquia formal da cooperativa se diluiria na perspectiva de homogeneização de todos os cooperados.

A alternância dos trabalhadores na execução, na coordenação de setores e no corpo administrativo, tem se mostrado um desafio na cooperativa, pois demanda um maior comprometimento de cada associado em se informar acerca do funcionamento de cada setor. O rodízio de funções não acontece plenamente dentro da COPAVI, devido à exigência interna por determinados patamares de produção, que não podem ser comprometidos pelo fato de o rodízio resultar 
em queda da produtividade dado o baixo conhecimento técnico de cooperados e coordenadores recém alocados em um setor. O que ocorre com frequência é a alternância de funções apenas no interior de um setor.

A organização do trabalho na COPAVI tem por objetivo contemplar necessidades técnicas e sociais de forma objetiva para cada atividade. Na cooperativa, os setores de produção são configurados segundo a sua importância para a produção total, levando à alocação dos trabalhadores de acordo com a demanda do setor em determinado momento. A distribuição das tarefas no interior dos setores é determinada pela Assembleia Geral, que define a participação de cada membro numa dada atividade a partir dos seguintes critérios: capacitação técnica; aptidão física; afinidade e disponibilidade. Todos os cooperados devem estar alocados em um setor e trabalhar, no mínimo, 176 horas mensais. Além disso, não se permite a concentração de membros de uma mesma família em um único setor. Os conteúdos e especificações técnicas das atividades de trabalho são determinados internamente pelos membros dos setores nas reuniões de seus grupos, permitindo que os membros interajam na prescrição da atividade. A presença dos trabalhadores nas instâncias que representam o poder decisório mostra a inclinação da COPAVI para a pratica da autogestão.

A carga semanal de trabalho na COPAVI não pode ultrapassar o máximo de 44 horas para os maiores de 18 anos, exceto em situações limite para o cumprimento de prazos de entrega da produção e mediante a aprovação da Assembleia Geral. Os jovens com idade entre 14 e 18 anos trabalham meio período e são remunerados com $85 \%$ do valor da hora trabalhada pelo sócio. O valor das horas trabalhadas pelos trabalhadores externos contratados pela cooperativa corresponde a 100\% do valor da hora trabalhada pelo sócio.

Um aspecto diferenciado na COPAVI é a participação da mulher no trabalho coletivo. As mulheres cooperadas integram o quadro de sócios e participam das decisões internas, tendo, como os homens, direito a um voto por cooperada. Isso se reflete na sua maior interação com as atividades administrativas e de execução da produção, fazendo com que seu trabalho seja tão importante quanto o trabalho dos homens, o que eleva sua estima dentro do coletivo e sua participação no interior da unidade familiar.

A distribuição das sobras correspondente ao faturamento da COPAVI se faz pela modalidade das horas trabalhadas. Em todas as atividades da cooperativa (produção, comercialização e administração) são computadas as horas trabalhadas pelos cooperados alocados em cada setor, e, após a aferição do resultado financeiro total de cada mês, é feito o rateio das sobras pelo total de horas, sendo determinado o valor de uma hora trabalhada. Esse valor é o coeficiente por que são multiplicadas as horas trabalhadas individualmente por cada cooperado, que vêm a receber sua participação nas sobras, como pode ser observado na Tabela 3. 
EID, F. \& CHIARIELLO, C. Organização do trabalho e processo decisório em cooperativas...

TABELA 3- RECEITA TOTAL, SOBRAS DISTRIBUÍDAS E VALOR DA HORA DE TRABALHO NA COPAVI (1994-2006)

\begin{tabular}{|c|c|c|c|}
\hline Ano & Receita Total & $\begin{array}{l}\text { Sobras } \\
\text { distribuídas }\end{array}$ & $\begin{array}{l}\text { Valor da hora } \\
\text { trabalhada }\end{array}$ \\
\hline 1994 & $\mathrm{R} \$ 81.700,00$ & $\mathrm{R} \$ 17.879,00$ & $\mathrm{R} \$ 0,24$ \\
\hline 1995 & $\mathrm{R} \$ 106.535,00$ & $\mathrm{R} \$ 12.188, \mathrm{OO}$ & $\mathrm{R} \$ 0,16$ \\
\hline 1996 & $\mathrm{R} \$ 145 \cdot 359, \mathrm{oO}$ & $\mathrm{R} \$ 27.819, \mathrm{oo}$ & $\mathrm{R} \$ 0,37$ \\
\hline 1997 & $\mathrm{R} \$ 197.479,00$ & $\mathrm{R} \$ 28.117, \mathrm{oo}$ & $\mathrm{R} \$ 0,36$ \\
\hline 1998 & $\mathrm{R} \$ 213.761,00$ & $\mathrm{R} \$ 32.286, \mathrm{oO}$ & $\mathrm{R} \$ 0,46$ \\
\hline 1999 & $\mathrm{R} \$ 257.482, \mathrm{oO}$ & $\mathrm{R} \$ 36.567,00$ & $\mathrm{R} \$ 0,5^{\circ}$ \\
\hline 2000 & $\mathrm{R} \$ 271.944,00$ & $\mathrm{R} \$ 40.000,00$ & $\mathrm{R} \$ 0,47$ \\
\hline 2001 & $\mathrm{R} \$ 282.596,00$ & $\mathrm{R} \$ 50.000,00$ & $\mathrm{R} \$ \mathrm{o}, 62$ \\
\hline 2002 & $\mathrm{R} \$ 299.300,00$ & $\mathrm{R} \$ 59.250,00$ & $\mathrm{R} \$ 0,67$ \\
\hline 2003 & $\mathrm{R} \$ 461.374,00$ & $\mathrm{R} \$ 80.725,00$ & $\mathrm{R} \$ 0,91$ \\
\hline 2004 & $\mathrm{R} \$ 459.900,00$ & $\mathrm{R} \$ 99.500,00$ & $\mathrm{R} \$ 1,09$ \\
\hline 2005 & $\mathrm{R} \$ 473 \cdot 300,00$ & $\mathrm{R} \$ 111.431,00$ & $\mathrm{R} \$ 1,21$ \\
\hline 2006 & $\mathrm{R} \$ 494.500,00$ & $\mathrm{R} \$ 127.200,00$ & $\mathrm{R} \$ 1,36$ \\
\hline
\end{tabular}

Fonte: dados fornecidos pela COPAVI. Elaborado com dados da pesquisa de campo realizada em novembro de 2007.

O sistema de distribuição das sobras por horas trabalhadas permite a remuneração do sócio de acordo com o quantum de tempo de trabalho dedicado à atividade. Até o mês de novembro de 2007, o valor médio da hora trabalhada ao longo do ano era de $\mathrm{R} \$ 1,41$. O montante distribuído como remuneração mensal das horas trabalhadas, em 2007, correspondeu a aproximadamente $\mathrm{R} \$ 250,00$ por cooperado. A cooperativa também antecipa cerca de $\mathrm{R} \$ 100,00$ por mês para cada família como adiantamento de sobras anuais. Assim, cada cooperado recebe, em média, um renda monetária mensal de $\mathrm{R} \$ 350,00$. Se levarmos em conta que cada núcleo familiar é geralmente composto por um casal de cooperados, a renda monetária familiar se aproxima de $\mathrm{R} \$ 700,00$. No entanto, a renda dos cooperados não é apenas monetária. A cooperativa é responsável pelas despesas referentes ao consumo de água e energia elétrica nas residências, além de prover as famílias de gêneros para o autoconsumo. Estima-se que essas despesas correspondam a 50\% da renda monetária, ou seja, $\mathrm{R} \$ 350$,oo por família. Somando o valor da renda monetária ao autoconsumo familiar, a renda total de uma família na COPAVI gira em torno de $\mathrm{R} \$ 1.050,00$, o equivalente a 2,76 salários mínimos em 2007 ( R \$ 380,00).

A situação dos cooperados, em termos de condições de moradia, alimentação e consumo, é relativamente melhor do que em assentamentos onde não se pratica o trabalho coletivo e também em relação à situação atual do trabalhador rural no país, como podemos observar no Quadro 1. 
QUADRO 1- COMPARATIVO DE RENDIMENTO DOS DOMICÍLIOS FAMILIARES

Média do rendimento monetário e não monetário mensal familiar dos domicílios rurais brasileiros - 2003*

Renda média familiar monetária e não monetária na COPAVI $2007^{* * * *}$

$\mathrm{R} \$ 1050,00$

* Fonte: IBGE (2008).

*** Referência de 2003: R \$ 466,28; corrigido a preços de 2007 (IPC-FIPE2003-2007= 15,6\%)

****Fonte: dados fornecidos pela COPAVI.

Elaborado com dados da pesquisa de campo realizada em novembro de 2007.

Ao longo do segundo semestre de 2007, a COPAVI realizou uma série de estudos para elaboração de um novo modelo de controle e medição do trabalho. $\mathrm{O}$ novo modelo considera, além das horas trabalhadas, um diferencial em função de determinadas condições as quais os trabalhadores são expostos quando executam o trabalho, em ordem decrescente de relevância: a) penosidade da atividade para o corpo; b) exposição ao calor; c) exposição ao sol; d) postura corporal durante a atividade; e) capacitação técnica requerida para a atividade; f) grau de interação com outros trabalhadores que a atividade proporciona; g) necessidade de tomada de decisões. Pelo novo sistema, cada item acima representa uma escala de valor adicional de remuneração. A cada cooperado caberia uma renda monetária fixa de $\mathrm{R} \$ 180,00$ e o montante residual das sobras seria distribuído conforme uma faixa de coeficientes. Para uma mesma atividade, o trabalhador pode se enquadrar em mais de uma das condições supracitadas. A proposta para que se discutisse uma outra forma de remuneração do trabalho partiu de membros do coletivo, que manifestaram em algumas reuniões a necessidade de se equacionar as atividades, recompensando diferentemente àquelas que requerem maior dispêndio de energia física.

Um outro debate que ocorre no interior da cooperativa diz respeito à contratação de mão de obra assalariada. A COPAVI contava, em 2007, com o6 trabalhadores diaristas, correspondendo a 8\% dos 49 trabalhadores na cooperativa. A presença de mão de obra assalariada se dá em função do aumento na demanda por produtos derivados da cana, sendo essencial o incremento de trabalhadores no setor em momentos de pico da colheita e do processamento da cana. Embora o objetivo da cooperativa seja a execução de todas as atividades pelos sócios, verifica-se um déficit de trabalhadores cooperados para plena utilização da capacidade instalada. Se por um lado há poucos trabalhadores dispostos a integrar os quadros da COPAVI, em razão da coletivização da propriedade dos ativos, por outro lado ocorre a recusa de novos sócios pelo coletivo. Os cooperados expressam apreensão em permitir o ingresso na cooperativa de pessoas relativamente desconhecidas. Mesmo com o advento do estagio probatório, verificou-se pouca aceitação de novos cooperados nos últimos anos. Os sócios da cooperativa têm a expectativa de que o quadro social se renove com a permanência dos seus filhos e suas famílias dentro da cooperativa. 
EID, F. \& CHIARIELLO, C. Organização do trabalho e processo decisório em cooperativas...

\section{Considerações Finais}

Tivemos por objetivo proceder à análise do processo decisório e da organização do trabalho em uma cooperativa tradicional e em uma cooperativa popular, cujas modalidades apresentam especificidades distintas. A discrepância é visível entre uma e outra no que tange à estrutura organizacional e societária, bem como a finalidade de suas atividades.

Certamente são alguns os fatores limitantes para uma análise comparativa distinta entre ambas: a) enquanto COCAMAR possui mais de 6600 associados e presta serviços comerciais aos cooperados, beneficiando sua produção e a intermediando com o mercado, a COPAVI é uma cooperativa de produção agrícola composta por 43 cooperados. Pela natureza das atividades e pelo número de associados, é latente que a participação direta dos sócios no processo decisório seja mais intensa na COPAVI; b) os associados da COCAMAR são proprietários e produtores rurais individuais, concentram maior interesse nas decisões e na organização do trabalho em seu próprio estabelecimento, mantendo relação apenas contratual com a cooperativa. Já os sócios da COPAVI são trabalhadores rurais que dependem exclusivamente dos resultados do empreendimento, resultando em um maior interesse pela organização do trabalho coletivo e da democracia interna na cooperativa.

Com base nestas considerações, podemos chegar a algumas conclusões referentes à gestão das duas cooperativas:

A gestão da COCAMAR, no que diz respeito à sua política empresarial, se revela nitidamente voltada para as exigências do mercado (market oriented), identificando-se com empresas tipicamente capitalistas. A elaboração do planejamento de médio e longo prazo da cooperativa é norteada essencialmente pela racionalidade econômica, impressa tanto nas determinações advindas do conselho de administração quanto na execução das atividades por parte de seu quadro de profissionais.

A partir da reclassificação do quadro social no início da década de 1990, com a exclusão de mais de sete mil cooperados, optou-se pelo estabelecimento de requisitos estritamente econômicos para a composição do quadro social. Assim, a cooperativa passou a aplicar a heterogestão, por meio da seleção de sócios de acordo com sua capacidade econômica e da contratação de profissionais para execução das atividades. As prioridades da cooperativa, em 2007, podem ser resumidas em três objetivos principais: a) crescimento da empresa e intensificação do relacionamento econômico com seu sócio cooperado; b) estabelecimento da empresa no segmento do agronegócio com capacidade competitiva; c) gestão moderna e baseada na racionalidade técnica.

Diferentemente das prioridades de gestão da COCAMAR, a COPAVI assume outros compromissos com seus cooperados: prover o sustento das famílias; proporcionar boas condições de moradia; garantir o direito à educação de 
seus filhos.

A democracia interna, na COPAVI, possui uma forte determinação pela base, através dos núcleos de famílias, e por se tratar de um empreendimento com número pequeno de associados, o que possibilita um fluxo intenso de informações, efetivando a democracia e evitando a criação de classes internas. No entanto, há na COPAVI grande dificuldade em estimular a participação dos sócios na gestão, quer na administração da cooperativa, quer na coordenação dos setores. Consequentemente, o rodízio de funções se mostra ineficiente, ocorrendo (quando ocorre) apenas no interior dos setores.

A COPAVI busca gerir a organização do trabalho de acordo com a capacitação e aptidão dos cooperados. Mas a baixa alternância entre os setores de produção acaba por formar trabalhadores especialistas. Nesse ponto, há responsabilidade concorrente entre a direção da cooperativa, os coordenadores dos setores e os cooperados. A direção da COPAVI pressiona pelo cumprimento das metas de produção em cada setor, ao passo que seus coordenadores não se propõem a realizar a rotação dos postos de trabalho, sob o risco de redução na produtividade do setor. Os cooperados, por sua vez, se acomodam em determinada função, geralmente as de execução, se esquivando de atribuições mais complexas.

Quando aumenta a importância dos subsetores responsáveis pela produção com maior valor agregado e retorno financeiro (como é o caso dos subsetores de cana-de-açúcar e derivados do leite), os cooperados neles alocados estabelecem demandas específicas. A reivindicação dos trabalhadores especializados colaborou para que a direção da COPAVI elaborasse, em 2007, um projeto para diferenciar a remuneração entre as atividades. A diferenciação na remuneração do trabalho pode vir a ter um caráter positivo, estimulando os cooperados a participarem das atividades em todos os setores. Do contrário, pode implicar no sectarismo, caso a cooperativa canalize todas as suas energias para alguns setores de destaque, com baixo rodízio de funções, resultando em maior prestígio de um pequeno grupo de trabalhadores detentores de conhecimentos específicos. Nesse caso, a equidade interna pode ser comprometida, elevando a concentração de poder e, no limite, talvez conduzir à heterogestão dentro do empreendimento, algo que, historicamente, demonstraria ser o início do fim da cooperativa autêntica.

Entretanto, ao mesmo tempo em que se acentua o debate sobre a diferenciação na remuneração do trabalho, a cooperativa sinaliza com a necessidade de revitalização dos subsetores de plantação e horta e com o aumento do comercio direto com o consumidor. A ressignificação destas atividades, importantes nos primórdios da cooperativa, atualizaria a motivação coletiva pretérita. O estágio de desenvolvimento da cooperativa em 2007, 14 anos após sua fundação, resulta de um processo que não se deu de modo espontâneo, fortuito, e sim revestido de muito trabalho, realizado por um coletivo de trabalhadores rurais. 
EID, F. \& CHIARIELLO, C. Organização do trabalho e processo decisório em cooperativas...

A partir dos referenciais teóricos e das investigações empíricas realizadas na COCAMAR e COPAVI, podemos apontar algumas singularidades na democracia interna e organização do trabalho nestes empreendimentos (Quadro 2).

QUADRO 2-DEMOCRACIA INTERNA E ORGANIZAÇÃO DO TRABALHO

\begin{tabular}{|c|c|}
\hline COCAMAR & COPAVI \\
\hline Representatividade da base é baixa & Representatividade da base é alta \\
\hline Aplicação da heterogestão & Aplicação da autogestão \\
\hline Prevalece o assalariamento & Prevalece a cooperação \\
\hline Polivalência & Politecnia \\
\hline Separação entre planejamento e execução & Integração entre planejamento e execução \\
\hline $\begin{array}{c}\text { Seleção dos sócios em função da capacidade } \\
\text { econômica }\end{array}$ & $\begin{array}{c}\text { Seleção dos sócios em função da } \\
\text { disposição à cooperação coletiva }\end{array}$ \\
\hline
\end{tabular}

Por fim, espera-se que o presente trabalho venha a contribuir para um maior entendimento sobre o movimento cooperativista no Brasil, movimento este que tem crescido nos últimos anos, motivando a investigação sobre sua trajetória.

\section{Referências}

BENETTI, M. D. (1985). “As relações entre estado e cooperativismo: análise do período 1933-37.” In: BENETTI, M. (org.). Desenvolvimento e crise do cooperativismo empresarial do R.S: 1957-84. Porto Alegre: F.E.E.

BIALOSKORSKI NETO, S. (2002). Estratégias e cooperativas agropecuárias: um ensaio analítico. Viçosa: Seminário de Política Econômica e Cooperativismo e Agronegócios.

BIALOSKORSKI NETO, S. (2001) "Virtual cooperatives in Brazil and the globalization process.” Journal of Rural Cooperation, (29): 153-165.

BIALOSKORSKI NETO, S. (1998). Ensaios em cooperativismo. Ribeirão Preto: FEA-USP.

COCAMAR (2007). Relatório 2006. Maringá, 2007.

CHRISTOFFOLI, P. I. (2000). Eficiência econômica e gestão democrática nas cooperativas de produção coletiva do MST. São Leopoldo: Monografia para o curso de especialização superior em cooperativismo, UNISINOS.

CONCRAB (1996). Cooperativas de produção: Questões Práticas. São Paulo.

COSTA, D. R. de M. (2005). Rating de cooperativas agropecuárias: uma contribuição metodológica. Piracicaba: Dissertação de Mestrado, ESALQ/USP, Programa de Pós-graduação em Economia.

CRUZ, A. C. M. (2006). A diferença da igualdade: a dinâmica da economia solidária em quatro cidades do Mercosul. Campinas: Tese de Doutorado, UNICAMP, Instituto de Economia. 
DUARTE, L. M. (1986). Capitalismo e cooperativismo no Rio Grande do Sul. Porto Alegre: ANPOCS.

FLEURY, M. T. (1980). Cooperativas e produtores agrícolas em uma sociedade capitalista. São Paulo: Tese de Doutorado, USP, Departamento de Sociologia.

FRANÇA FILHO, G. C. (2002). “Terceiro setor, economia social, economia solidária e economia popular: traçando fronteiras conceituais.” Bahia Análise \& Dados (1): 9-19.

GAIGER, L. I. (2006). “A economia solidária diante do modo de produção capitalista.” URL: http://www.ecosol.org.br. Acesso em 25 de julho de 2006.

LEVY, Y. (2001). “Globalization and the cooperative difference.” Journal of Rural Cooperation (29): 105-114.

LISBOA, A. M. (2006). "Desordem do trabalho, economia popular e exclusão social: algumas considerações.” URL: http://www.ecosol.org.br/textos. Acesso em 20 de julho de 2006.

MENEGÁRIO, A. H. (2000). Emprego de indicadores sócio-econômicos na avaliação financeira de cooperativas agropecuárias. Piracicaba: Dissertação de Mestrado, ESALQ/USP, Programa de Pós-graduação em Economia.

PANZUTTI, R. (1996). Estratégias de financiamento das cooperativas agrícolas no estado de São Paulo. Campinas: Tese de Doutorado, UNICAMP, Programa de Pós-graduação em Economia.

SANTOS, V. D. (2001). Crescimento, crise e reestruturação da Cooperativa de Cafeicultores e Agropecuaristas de Maringá - COCAMAR (PR). Maringá: Dissertação de Mestrado, UNIPAR, Gestão de Agronegócios.

SAVIANI, D. (1989). Sobre a concepção de politecnia. Rio de Janeiro: Fundação Oswaldo Cruz.

SINGER, P. I. (2002). Introdução à economia solidária. São Paulo: Fundação Perseu Abramo.

TAUILE, J. R. \& RODRIGUES, H. (2006). “Economia solidária e autogestão: a criação e re-criação de trabalho e renda.” URL: http://www.unitrabalho.org.br/textos. Acesso em 12 de abril de 2006.

ZYLBERSTAJN, D. (2005). "Quatro estratégias fundamentais para cooperativas agrícolas.” In BRAGA, M. \& REIS, B. (orgs). Agronegócio cooperativo: Reestruturação e Estratégias. Viçosa: UFU/DER, pp. 77-97.

Submissão: 26 de agosto de 2008 Primeira resposta: 01 de outubro de 2008 Aceite: 11 de novembro de 2008 
